\title{
Who's Running the Road?: Street Railway Strikes and the Problem of Constructing a Liberal Capitalist Order in Canada, 1886-1914
}

Eric Tucker

Osgoode Hall Law School of York University, etucker@osgoode.yorku.ca

\section{Source Publication:}

Law and Social Inquiry. Volume 35, Number 2 (2010), p. 451-485.

Follow this and additional works at: https://digitalcommons.osgoode.yorku.ca/scholarly_works

Part of the Labor and Employment Law Commons

c) (1) $(9)$

This work is licensed under a Creative Commons Attribution-Noncommercial-No Derivative Works 4.0 License.

\section{Recommended Citation}

Tucker, Eric. "Who's Running the Road? Street Railway Strikes and the Problem of Constructing a Liberal Capitalist Order in Canada, 1886-1914." Law and Social Inquiry 35.2 (2010): 451-485.

This Article is brought to you for free and open access by the Faculty Scholarship at Osgoode Digital Commons. It has been accepted for inclusion in Articles \& Book Chapters by an authorized administrator of Osgoode Digital Commons. 


\section{In Defence of Quasi-Contract Dan Priel $^{*}$}

Restitution scholars are almost unanimous in rejecting the term quasi-contract. This essay challenges this view. It begins by demonstrating that many debates among restitution scholars are in fact debates about the boundaries of consent-based liability. This serves as an introduction to the main thesis advanced, which is that theidea of quasi-contract, which is supposed to covercases in which the parties would have made a contract if conditions allowed them to do so, helps to explain the doctrine better than the conclusory language of unjust enrichment. The essay concludes by situating the argument within the growing literature on the normative foundations of restitution. It argues that quasi-contractual liability should be understood not as part of unjust enrichment, but as a different basis of liability that can help us see what liability for unjust enrichment might be: liability grounded in notions of fairness.

\section{INTRODUCTION}

The term 'quasi-contract', once used to describe the area of law now called 'restitution' or 'unjust enrichment', is now out of favour. Peter Birks, the preeminent restitution scholar of his generation, explained why:

'Quasi-contract' says only that the matter is not contract. So far as it suggests that there is a sort of contract, it deceives, unintelligibly. A quasi-sparrow is not a sparrow. In what respect it might resemble sparrows is left to speculation ... A deceptive name is a constant impediment. ${ }^{1}$

Talking about the close term of 'implied contract' Andrew Burrows was equally hostile. The notion, he argued, was fictional and said nothing about why the promise should be implied. By masking

\footnotetext{
${ }^{*}$ *Assistant Professor, Osgoode Hall Law School, York University. I presented an earlier version of this essay at a workshop in Osgoode Hall, and I thank participants there for their comments. For conversations on some of the issues discussed in this essay I also thank Prince Saprai. Finally, I thank two anonymous referees for the Modern Law Review for their comments.
} 
the underlying basis for recovery the theory obscured the important similarities and differences between the cases reversing benefits received. Moreover it was contrary to the rule of law for judges to reach decisions without properly explaining their reasoning. ${ }^{2}$

Strong words. But also, I think, quite problematic. One wonders, for instance, about Birks and Burrows's commitment to the elimination of fictions when both frequently use the concept of 'constructive trust', which wears its fictional nature on its sleeve. One wonders whether it is clarity of language that they are after when they both frequently use the term 'unjust enrichment' - Birks even used this term as the title of the book from which the quote comes - only to stress elsewhere how little their topic has to do with justice, with Birks going so far as to say that '[b]ut for the need to retain a trace of nor mativity, one might just as well speak of pink enrichment'. ${ }^{3}$ Burrows's claim that judges who relied on this term violated the rule of law by not explaining their reasoning is odder still. All those judges who presumably obscured their real reasoning by using the concept of 'quasi-contract' instead of the principle that supposedly really explained their decisions did so (one would think) according to their best understanding of the law, indeed by following what the law by everyone's reckoning at the time was. How could doing so be a violation of the rule oflaw? Burrows faces a dilemma: if there is a separate principle of unjust enrichment that was part of the law even before it was endorsed by the courts, that would contradict his claim to be describing the law of restitution as it is found in the 'decided cases'. ${ }^{4}$ But if the principle was not part of the law at the time, then the courts were not violating 
the rule of law by not following it. And if it is the obscurity of the labels that Burrows is worried about, violating the rule of law by making its content incomprehensible to laypeople, one wonders how much sense the uninitiated will make of terms like 'negative benefit', 'incontrovertible benefit', free acceptance', 'subjective devaluation'and a host of others that are stock in trade for the contemporary restitution lawyer.

There is, however, perhaps a more plausible version of this criticism. In early treatments of the subject now known as restitution or unjust enrichment it was thought that the law of quasi-contract is filled by whatever is not contract and tort, including obligations arising from statute or judgment. ${ }^{5}$ But telling us only that liability in this area should be treated 'as if it had a contractual origin', ${ }^{6}$ by itself placed no constraint, not did it provide any guidance as to the content of the obligation in question. For those who worried that terms like 'unjust enrichment' or 'ex aequo et bono'would send the courts down the dangerous path of 'vague jurisprudence which is sometimes styled "justice as between man and man", 7 quasi-contract may have seemed even more open-ended. In this essay I will nonetheless argue that if we are interested in making sense of the law, then the term 'quasi-contract' can actually be quite helpful and illuminating for understanding part of the law now classified as unjust enrichment. ${ }^{8}$

One purpose of this essay, then, is clarificatory: I aim to show that on the issues in question the language of unjust enrichment can be obscuring, vacuous, and misleading. It is obscuring when it stands in the way of recognising the normative considerations that govern the cases at hand; it is vacuous when it does not 
provide any normative guidance; and it is misleading when it suggests remedies the law does not actually provide. I will argue that looking at those cases from a contractual perspective is helpful on all fronts. My more general and theoretical concern is to question some aspects of doctrinal scholarship and the focus it places on identifying the 'correct' taxonomy of legal rules by carefully attending to legal doctrine. This, I will argue, is a hopeless goal without a clearer understanding of the extra-legal normative issues at hand.

Here is how I plan to proceed. In the first section I argue that when examining the language and considerations used to determine whether liability should be imposed in many cases treated as examples of restitutionary liability, we see that they are better understood as cases about the limits of consent-based liability. I argue that considering these cases from a contractual perspective identifies the instances in which liability is imposed and those in which it is not better than the conclusory language of restitution. In the second section I examine the question of remuneration for assistance given at times of emergency. In this context I show that restitution law is not only unhelpful but is in fact misleading, for it cannot explain the remedies that are typically awarded in such cases. I use this type of case to argue that once we recognise the contractual element in them, we can develop a more precise set of conditions under which liability should be imposed. In these cases it would be appropriate to call the liability 'quasi-contractual', because it would be imposed in cases where there is no valid contract between the parties, but which are fruitfully analysed as though there is one. In the third section I turn from doctrinal details to the broader picture and consider the relevance of the 
preceding discussion to the question of the theoretical foundations of restitutionary liability, a topic that received considerable attention in recent years. I argue there that there is no reason to think that the foundation of the cases I considered earlier lies in the notion of corrective justice; instead I suggest that the normative basis of these cases should be traced to norms of fairness. I show how considerations of fairness play a role in explaining why liability is imposed in quasi-contractual cases, and I suggest more tentatively what role fairness might have in underlying liability for unjust enrichment.

\section{THE BOUNDARIES OF CONSENT}

\section{The general rule: no liability for unconsented services}

The basic rule with regard to unconsented services is that the recipient is not liable to pay for the benefit he received. For instance, if you mistakenly think I asked for my house to be painted, and you did so while I was away, I do not have to pay you for the service, even if I like the house better now, and even if its market value has increased as a result. I do not have to pay even if I intended to get it painted in exactly the same way upon my return. At first blush this seems to be the exact opposite of the rule with regard to mistakes that confer benefits in kind. If you mistakenly send me a parcel that was intended to someone else, Ido not thereby become the owner and you are entitled to get it back. Why does the law treat these cases so differently? 
Jack Beatson tried to solve this conundrum by arguing that in the case of unconsented services there is no enrichment. ${ }^{9}$ But there is no good reason to say that as a matter of law there was no enrichment in these cases: No doubt there will be services that I will never agree to pay for, and probably some that I would even demand payment to receive, but this is a factual matter on which the parties could present evidence. It might be argued, then, that the problem is not that there is no enrichment, but that there are great difficulties in measuring it, and that the law's response - of which there are many other examples $^{10}-$ is to have a substantive rule whose real reason is procedural. To allow parties to argue on this matter would require the defendant to prove that she has not benefited subjectively from the service, and such claims would be hard to verify. While this is a possible explanation, it is not clear that assessing the value of the enrichment in the case of services is an insurmountable obstacle. After all, there is a market for most services, and even if we assume that the recipient was unwilling to pay the market price for the service, the law's reluctance to make any effort to find the subjective value for the enrichment to the claimant may seem odd. Low as it might be, the value of the service to the claimant will almost always be more than zero. Why not allow the provider of the unconsented service restitution for this enrichment? The alternative could be that instead of denying liability in these cases, claimants would be allowed to present their case by the standards of proof of civil trial, and if they could not provide sufficient evidence of the defendant's gain from their service, they would lose their case. 
The higher administrative costs in the case of services are no doubt part of the problem, but there is more to this case than that. The difference between unconsented services and cases of mistaken provision of money or a material object is that in the latter type of case we can cancel the mistaken action, whereas in the case of the typical mistaken service we cannot. If I mistakenly get a physical object or a mistaken money payment and am then required to give them up, I stand in exactly the same position as I would have if the mistake had not occurred. If someone cuts my lawn without my request and I decide that I do not want to pay the market price for it, the cut grass blades cannot be reattached. Thus, the effect of the unrequested service is to force upon me a new state of affairs with regard to my entitlements. Even supposing the sum I would have been willing to pay for the service is known if I elected to have it, forcing me to pay the sum would in effect force me into a contract. Denying recovery for unconsented services deters people from trying to circumvent the market by conferring a service on others and then coming forward to collect the bill.

But why does the law try to prevent circumventing the market? Are there no cases in which people would benefit from such services by getting a service they would otherwise never get, or at least not as cheaply? No doubt such cases are imaginable, and the further we are from conditions of perfect market competition the more likely it is that we will encounter such cases. But in liberal societies autonomy is valued to such a degree that the assumption is that intervention in such cases is always problematic. To those who consider autonomy to be 
intrinsically valuable, these cases are problematic for eliminating individual choice. Those who believe that autonomy is valuable because individuals are usually best positioned to promote their well-being are likely to be suspicious of suggestions that the law should create such transactions against the better judgment of the individual. (Indeed, many of the differences between the political ideologies ranging from libertarianism to communism on questions ranging from the optimal 'size' of government to the right approach to interpreting contracts can be explained by the degree to which its proponents trust people's ability to know on their own what is likely to promote their wellbeing.)

The assumption underlying the rule, then, is that contracts are important for individuals' autonomy because they are a vehicle for individuals to determine what shape their lives will take and perhaps also because they are a means for getting objects and services that improve individuals' well-being. And the corresponding assumption is that forcing people to pay for services they did not request will therefore negatively impact their autonomy. ${ }^{11}$ A related reason has to do with the fact that conferring a service on another, unlike mistakenly paying them, almost inevitably involves violating their autonomy by interfering with their body or their property in the first place. (This is why a gift of a service is typically a gift of an option to get the service, not the service itself.)This is not true in the case of mistaken payments (or self-interested actions that have positive externalities). 


\section{The borderline case: free acceptance}

Free acceptance is a term coined by Goff and Jones to describe the case of a person who 'ha[s] been benefited by the receipt of services ... unless he has accepted them ... with an opportunity of rejection and with actual or presumed knowledge that they were to be paid for' ${ }^{12}$ An oft-discussed example of free acceptance provided by Birks is of a window-cleaner [who] begins[s] to clean the windows of my house. I know that he will expect to be paid. So I hang back unseen till he has finished the job; then I emerge and maintain that I will not pay for work which I never ordered'. ${ }^{13}$

Should cases of free acceptance give rise to restitutionary liability? Birks believed that they should. ${ }^{14}$ The crucial element in Birks's view is the fact that the recipient of the service knew that the claimant expected to be paid for the service and yet chose not to reject it despite having an easy opportunity to do so. Other scholars have argued that cases of free acceptance should not give rise to liability. In effect they have argued that cases of free acceptance should be treated under the general rule that denies liability for unconsented services. ${ }^{15}$ One central reason for this conclusion, as Burrows put it, is that

there would be no injustice in my not paying a risk-taker. For even if I can be said to have acted shabbily, this is matched by the fact that the claimant was a risk-taker - without any inducement he gambled on my willingness to pay. Why should we now want to protect him against the very risk that he undertook? ${ }^{16}$ 
At first, this seems exactly in line with the argument developed in the previous section. Contract is the legal mechanism with which people can regulate their future risks, and those who avoid it when they could have used it do not deserve the law's assistance. We can imagine a spectrum at one end of which there is no contract. This case is analytically identical to a blank contract in which a provider of a service or a good takes the risk as to the willingness of the recipient to pay for service as well as the amount she will pay after the service is provided. (Of course, contract law will not enforce this kind of 'contract', and it will not do so, inter alia, for the reason Burrows mentions in the passage just quoted.) We can then imagine a series of increasingly more complete contracts, that is, contracts that take care of more aspects of the transaction: first basic aspects like price, quantity, and quality; the contracts then begin to cover possible contingencies, beginning with ones that are fairly likely (temporary shortage in the supply of a certain raw material) and end at alien invasion. The more complete is the contract, the more expensive it is (both because of increasing costs of drafting and because of the greater likelihood that the parties will disagree on something and thus fail to contract). In a sense, contracting involves investing present money for future returns where parties are given a wide range of risk versus return options: the less one invests ex ante in making the contract, the higher is the risk that some contingency not covered in the contract will occur; but if ex post it turns out that the contingency has not occurred, then the costs incurred in adding this contingency to the contract have been a waste, and so reduced the 
contracting parties' returns on their investment. ${ }^{17}$ On the other hand, the fewer the details found in the contract, the more likely it is that the parties will disagree on their respective obligations and the more difficult will it be to make factual determinations on the matter. For this reason beyond a certain point the law will not be willing to offer its (highly subsidised) service of dispute resolution to such transactions.

Against this theoretical background we can look at the question of free acceptance from a slightly different angle than usual: the question is not whether a risk-taker should be allowed to be protected by the law of restitution against the very risk he took, but rather whether an unconsented service provider should be considered a risk-taker at all. Put differently, the question that this example forces upon us is where must one stand on the spectrum just mentioned to be able to enjoy the state-provided insurance mechanism known as 'contract law'.

Neither Birks nor those debating with him explicitly discussed the question of free acceptance in terms of the limits of the law's protection of voluntary undertakings. But the point on the spectrum where one is entitled to enjoy the benefits that come from making a contract is not a law of nature: in some legal systems one can find oneself with a binding contract more easily than in others. ${ }^{18}$ The first step in my argument will therefore be to try to show that, though this is not explicitly how the debate on free acceptance is usually framed, it is in fact better understood as concerned with this question.

To begin with, the term 'free acceptance'includes the same word familiar from contract law as the mechanism for perfecting contractual obligations. More than 
verbal support is found in the rationales provided in the debates on free acceptance: when Birks first defended imposing liability in free acceptance cases he conceded that '[i]t would not have been possible to dispense with the contractual explanation if there were not a sound basis for imposing the restitutionary obligation'. ${ }^{19}$ This is quite revealing, because one would have thought (especially in the case of Birks) that the analysis should go from rules to legalconclusionsand not the other way around. If there is no good contractual explanation of such cases, the most natural conclusion should have been that there is no basis for liability at all. ${ }^{20}$ But turning Birks's point on its head it might be asked, if a contractual explanation is possible for these situations, why is restitutionary analysis necessary?

Leaving these somewhat technical points aside, let us look at the substance of Birks's argument. Initially, Birks formulated it thus: The claimant has conferred a benefit on the defendant expecting some return for himself and not intending to confer a gift upon the defendant... [W] hy should he not receive the value? ${ }^{21}$ In fact, when Birks specified the conditions for the imposition of liability in cases of free acceptance one of them is that the defendant 'must have known of that intent [ie, a non-gratuitous intent] to confer a benefit'. ${ }^{22}$ Birks later refined and qualified his earlier position and argued that the unjust factor in free acceptance is the unconscientious rejection of an opportunity to save the intervener from the risk he was running' ${ }^{23}$ This, however, seems a rather unusual position: the law does not typically impose liability on people who have an opportunity to save people from running risks. So by itself this cannot be an unjust factor. What makes this 
situation (if it does) unjust is the existence of a special relationship between the claimant and the defendant; and we are likely to conclude that such a relationship existed exactly in those situations in which a contract or something like it was governing their relationship so that we may conclude that each party has undertaken, explicitly or implicitly, to reduce some of the risks the other was running.

Another defender of free acceptance, Ewan McKendrick, also resorted to the language familiar from contract to describe the basis of restitutionary liability. He discussed a case in which one party delivered steel nodes to another while the parties were negotiating the terms for a contract. The contract eventually failed to materialise due to a certain disagreement between the parties and the delivering party sued. ${ }^{24}$ McKendrick contends that the basis for liability is that the recipients 'requested steel nodes of a particular quality and in a particular order', which the claimant then delivered. Even if there is no formal contract here, it is clear that the liability is grounded in consent. With regard to the appropriate remedy in such a case McKendrick even said that 'a court [could] take account of the expectation of the buyer and provide protection accordingly'. ${ }^{25}$

It is not only the defenders of free acceptance who are better understood as arguing for redrawing of the boundaries of contract; the same is true of arguments made by the proposed doctrine's critics. Some of them have asked why we should impose an obligation on the defendant in such a case when the service provider could have easily asked the defendant whether she wanted the 
service (ie when what is normally considered the straightforward contractual route was so evidently open). ${ }^{26}$ This claim could be restated as questioning the desirability of expanding the law's protection to those who have behaved in a manner that imposes unnecessary costs on others and on the judicial system. For similar reasons, critics of free acceptance have referred to the limits on acceptance of contractual offers by silence, and criticised the fact that Birks's notion of free acceptance can bring in liability through a restitutionary back door after contractualliability has been denied at the front. ${ }^{27}$

Though sceptical of the view that restitutionary liability should be imposed in cases of free acceptance, critics of the idea make it clear that something not far from it - even if not a fully-fledged contract - deserves legal protection. In determining whether restitutionary liability should be imposed, Burrows, for example, invokes what he calls the 'bargained-for' test, which he explicitly says is supposed to cover cases of void, unenforceable, incomplete, or anticipated contracts'. ${ }^{28}$ And his examples of cases in which (restitutionary) liability should be imposed when people try to subvert contractual mechanism all come from contractual settings.

Also revealing is the remedy a service provider would receive if he succeeds in a free acceptance claim. The standard remedy is quantum meruit as measured by the market price, which, when lacking any information to the contrary, is typically the price the parties would have agreed upon if they had made a contract. Consequently, in these cases, even though formally the protected interest is restitution, the reality in practice will coincide with the expectation interest. ${ }^{29}$ 
And to the extent that the recipient can challenge that price, it is by pointing to what Birks called 'subjective devaluation', ie by showing that she would only have agreed to contract for the service she received for less than the market price. Birks never considered the possibility of an opposite suggestion of 'subjective overvaluation', which suggests that he may have recognised that in a situation like this, a claimant who has already been protected from the risk of not having her claim legally recognised should bear the risk of proof of lower contractual price, even if it is one that she would not have agreed to. ${ }^{30}$

We see then that once we ignore existing legal categories, most debate on free acceptance is in fact concerned with the boundaries of consent-based liability. There is, however, one type of free acceptance that cannot reasonably be understood in contractual terms. In what Birks called 'secret acceptance' the recipient secretly hides at home when someone else provides her with a service. ${ }^{31}$ When the service is complete she comes out to inform the service provider that she will not pay. This is an extremely unlikely hypothetical, and even if we thought that such a case calls for the imposition of liability, its practical relevance would be small. No-one found in a situation such this would do the one thing that could lead to liability.

Despite its practical insignificance, this case is interesting because it is the one case in which Birks believes liability should not be imposed. This is revealing, because if Birks had really been committed to the notion of free acceptance and not to that of consent-based obligation, should there have been a difference between this case and other cases of free acceptance? Birks classifies free 
acceptance under the heading of 'defendant-sided restitution', ${ }^{32}$ and he argues that the reason why liability should be imposed in free acceptance cases is that 'shabbiness' of the recipient's behaviour. But if we focus on the recipient there hardly seems to be any difference between the cases of the secret recipient and that of the known recipient, as both have a similar opportunity to reject the service. If anything, the behaviour of the person who remains in hiding until the provider completes her work and then comes out to tease her, looks shabbier.

Compared with the artificiality and complexity that the free acceptance analysis requires from us, consent-based analysis makes the distinction between the cases of secret and known acceptance straightforward. Whether or not we ultimately decide to impose liability in cases of known acceptance the answer depends on whether we believe that there are good reasons for setting the boundary of consent-based liability before the point of a fully articulated agreement. Free and secret acceptance are very different in this regard, and while under certain conditions 'normal' free acceptance might be thought sufficient for entering the domain of consent-based liability, secret acceptance does not come even close.

If what I claim here is correct, it immediately raises the question of why the debate has not been conducted more explicitly in terms of the limits of consentbased liability or the boundary of voluntary obligations. Why, that is, has the debate not been about whether the requirements for entry into contract should be changed? The normative arguments and legal conclusions might have been 
roughly the same, but their 'location' would have been on the edges of contract law, rather than at the heart of restitution law. Arguably, this is the place where anyone concerned with the clarity of the law would have preferred this debate to have taken place.

There are several possible answers. First, the debate has mostly been conducted by restitution scholars eager to show that restitution law is a significant body of law. This is in line with their reinterpretation of various other areas of law that have been traditionally handled under other headings (eg, the outcomes of rescinded contracts) that restitution lawyers claim 'really'belong within the law of unjust enrichment or restitution. Restitution being close to these scholars' hearts, they may have been inclined to look at the issue through the restitutionary lens and not the contractual one. Second, for those who might find churlish the suggestion that restitution scholars simply want a larger chunk of the law for themselves, there may be a deeper reason for this tendency of enlarging restitution at the expense of contract. At least in English law, the fundamentals of contractual doctrine familiar to us today crystallised in the course of the nineteenth century and they have remained relatively stable for a long time. ${ }^{33}$ (By contrast, rules regarding the content of contracts once a contract is formed proved more flexible.) Perhaps by now these rules are perceived as so deeply entrenched and therefore no longer open to significant change.In contrast, restitution - still considered a relatively fertile ground whose boundaries are in flux - provides an easier location for adjusting the law. ${ }^{34}$ Finally, it might be said in response that it is a mistake to treat the rigid rules 
of entry to contract as a mere historical accident; rather, they reflect a substantive view about the sort of situations that should be covered by contract law.This, however, is simply to beg the question as to what the boundaries of contractual liability should be. There may be good reasons for maintaining fairly rigid limits to consent-based liability, but these should be stated clearly.The claim that there should not be liability in cases of free acceptance reflects this position, but it is obscured from view when restitutionary concepts are introduced into the discussion. For those who believe that there should be liability in some cases of free acceptance matters are even worse, for they have to explain how they can support rigid rules of entry to contract and at the same time support a doctrine that undermines these rules. It matters little that this doctrine does not formally affect contractual rules because it is treated as part of a different area of law, if its practical effect, as can be seen from the argument invoked in support of the doctrine, is to expand the scope of consent-based liability.

Incidentally, I think the explanation offered in the last paragraph goes some way to explaining why restitution law has flourished in English law, whereas in other countries - notably the United States - lawyers, and even more so academic lawyers, seem to be getting by without much need for it. ${ }^{35}$ In the US, courts and commentators are much more willing to question or change established doctrine on the basis of a more open discussion of the normative considerations underlying the doctrine, ${ }^{36}$ and perhaps as a result the rules regarding entry into contract have been eroded more than in English law. ${ }^{37}$ As a result there was 
simply much less of a need to develop alternative non-contractual doctrines, where revised contract rules sufficed. ${ }^{38}$

\section{THE LAW OF QUASI-CONTRACT}

So far I have sought to show that a significant chunk of what is now classified under restitution is normatively closer to the question of the boundaries of consent-based liability. It might be claimed, however, that this is not an argument in favour of a new kind of 'quasi-contractual' liability, but only a reason for discussing more openly, and perhaps relaxing, the appropriate requirements for entry to contract. Is this therefore merely an argument over words? To some extent this may be true: so long as we reach the 'right' decisions, that is, the optimal ones by whichever normative non-legal standards we adhere to, then labels may not matter much. To take an example from a different domain, some events can be treated both as breaches of contract and as torts of negligent misrepresentation; and even though the typical contract remedy is expectation damages and the typical tort remedy is reliance damages, their measure in such instances can be quite similar if we take lost opportunities into account. Comparative legal history likewise shows that often different legal frameworks overlapped on outcomes even when they differed in the way to get there. This is not hard to explain: legal classifications hardly ever operate in isolation from our sense of the correct disposition of the case.

Nonetheless the earlier discussion is important for it purported to rattle 
existing categories and to show how such categorisations can obscure discussion of the real issues at hand, as much as they sometimes help us by getting us quickly to a particular outcome. Labels send us down certain normative routes and can thus affect our judgments, especially in borderline cases when different classifications yield different outcomes. Once this is recognised, it is easier to accept the argument developed in this section, which poses an even more fundamental challenge to the boundaries of contract. It is here that the idea of quasi-contract can be particularly illuminating. Unlike the cases of free acceptance that are better explained as dealing with the limits of contract, cases of emergency service, the subject of this section, show how quasi-contractual liability is valuable exactly because they fall outside the boundaries of contract butare best explained by the relation they take to proper contractual relations.

\section{The limits of restitutionary analysis}

In a typical emergency case a person provides a service when the latter is unconscious and in mortal danger and cannot consent to the service. The question that interests us is not whether one may be liable to pay compensation if he fails to do so. On this matter, as is well known, the traditional common law answer is negative. Rather the question we are concerned with is whether one is entitled to remuneration for his services if he chooses to provide the service. Such claims have often proved successful in common law jurisdictions, and many times even when the treatment failed. ${ }^{39}$ It is worth examining first how such cases are 
analysed in restitutionary terms.

Burrows offers such an account using the analysis familiar to English lawyers of locating a benefit, examining whether it was unjust and whether the enrichment is at the claimant's expense. (I disregard the question of defences.) Examining the first two elements of restitutionary liability reveals the artificiality of the unjust enrichment route. According to Burrows, the unjust factor in this case is the policy-motivated desire of the law to encourage people to intervene to preserve the health and property of others'. ${ }^{40}$ The first odd thing about this suggestion is the attempt to force it into the restitutionary category. We do not need to rely on restitutionary analysis to impose liability: at least within the Birksian framework (that Burrows accepts) such liability could be placed within the miscellaneous category. Placing it within the category of restitutionary is justified, then, only if doing so helps understanding both of why liability is imposed and the scope of liability. In fact, it does neither.

It is hard to see how such a policy consideration could be an 'unjust factor' unless the term 'unjust factor' is stripped of all meaning. After all, any goal we wish to promote can be dubbed a 'policy'we wish to promote, and thus become an unjust factor: the performance of contracts and the prevention of accidents are also policies society may wish to promote. Recognising policy motivated unjustfactors leads to the very conclusion restitutionary lawyers fought so hard against, namely that restitution is the name we give to all liability that does not fall under contract or tort. In other words, the attempt to cover rescue cases comes at the expense of 
completely emptying restitution law of normative coherence and undermining the main reason that has restitution scholars identify it as a distinct legal category. ${ }^{41}$ In saying this I do not wish to deny that there are policy considerations underlying the decision to impose liability in these cases. One would think (or at least hope) that there is some good policy behind all laws.All I wish to say is that the idea of such cases as explained by the 'policy-motivated', unjust factor does little to advance our understanding of the outcome of these cases.

A more significant problem exists with a different element of the traditional restitutionary analysis, that of enrichment (thus posing a problem also to alternative restitutionary analyses like the one used in Canada, which does not require the showing of an 'unjust factor').The facts of a famous American case, Cotnam $\mathrm{v}$ Wisdom $^{42}$ (Cotnam), provide a useful point of departure. In this case the claimants, two surgeons, sued the estate of one Harrison they had operated on in an attempt to save his life after a car accident. Because the deceased was unconscious the medical services were provided without Harrison's consent.The court ruled in the claimants'favour despite the fact that the operation failed and the patient died.

If we want to fit such a case within a restitutionary analysis we need to find the benefit that the recipient got from the service. What could that benefit be? Burrows suggests that the the very necessity ... suggests that the intervention was an incontrovertible negative benefit'. ${ }^{43}$ Negative benefit is Burrows's term for having an expense one was required to pay saved because it was paid by someone else. But the question in cases of emergency is exactly what the expense 
that the unconsented service provided is.There are two possibilities here: one is that the 'negative benefit' is the cost of the emergency service; the other is that the 'negative benefit' is having the losses associated with the emergency prevented.According to the first interpretation, the claimant is entitled to benefit for the service she provided only if it was successful. In that case, however, her entitlementis measured by the 'negative benefit'she saved the defendant and she is entitled to a significant portion of this benefit.This is the ex post analysis. The ex ante analysis is one that does not measure whether the claimant succeeded, but whether she tried with the requisite diligence; if she did, she is entitled to the ex ante cost of that service whether or not the service turned out successful.

Usually restitution scholars analyse such questions from the perspective of the benefit the recipient of the service actually made, that is, ex post. But Cotnam is a good example of the other option: in Cotnam the claimants succeeded in their claim despite failing. In fact, cases like Cotnam show why the expost analysis is problematic whether or not the service is successful. If the treatment fails, then the ex post benefit of the recipient is zero, and so the claim should fail. If on the other hand the operation is a complete success and the recipient returns to normal life, then the ex post benefit to the recipient is much higher than quantum meruit, what restitution scholars believe is the correct remedy ${ }^{44}$ which is typically the market price for the service provided. ${ }^{45}$ In fact, the law provides us with an example of such an ex post rule: maritime law entitles a rescuing ship to up to 50 per cent of the value of what is rescued from a sinking ship, but this entitlement 
depends on success; failed rescuers receive no remuneration at all. ${ }^{46}$

If such cases cannot be adequately analysed in restitutionary terms, how should they be considered? In his latest writings Birks turned back on his earlier view and suggested such cases are best filed under a miscellaneous category, which includes a hodgepodge of all claims that have in common only the fact that they are not based in contract, tort, or restitution. Though the change in view is a characteristic example of Birks's intellectual honesty, it is in some sense an admission of failure, because this category includes such different cases that we have absolutely no guidance as to how these cases should be treated. ${ }^{47}$

Let us now see whether the notion of quasi-contract can help us understand what is at stake. Cases of emergency take us beyond what has already been discussed, because here we need to ask whether to impose liability in certain circumstances in which no contract has been made between the parties but when we have good reason to believe that such a contract would have been made if the parties had had the opportunity to do so.This analysis is more fitting for these cases because by trying to find what the parties would have contracted for, it adopts an ex ante perspective. Interestingly, once again we see that commentators who reject the quasi-contractual analysis end up explaining the situation by invoking contractual concepts. For example, in explaining why liability should be imposed only on successful attempts, Burrows writes:'A reasonable man [sic] would surely pay for someone to try to rescue his drowning daughter or to try to save his burning house'. ${ }^{48}$ Burrows comes close to stating the quasi-contractual rationale for imposing liability: the reason why liability should be imposed in such cases is 
because people would have been willing to pay for the service (even without the guarantee of success), if they had had the opportunity to do so.

Within a quasi-contractual analysis it is not difficult to explain why liability need not be limited to successful attempts. In many contracts for service, the service provider does not promise a certain result, only a certain degree of effort. If the promisor fulfils her contractual liability by performing to that level, she does not breach her contractual obligation even if the service she provides does not match a certain desired outcome. By contrast, in principle, if the promisor fails to perform to the same degree required by the contract, she breaches the contract even if the non-contracted yet desired outcome is achieved. ${ }^{49}$

\section{The conditions for imposing quasi-contractual liability for emergencies}

The previous section has shown that attempts to explain emergency rescue fail both in terms of fitting restitution to the doctrine and also in forcing upon the subject a loosening of its categories that leaves it almost devoid of normative content. In this section I aim to show that a quasi-contractual analysis can do better. A true emergency situation that should give rise to quasi-contractual liability exists in the following situation: an uncontracted-for service is provided when (a) transaction costs for the contract are prohibitively high; (b) had the service not been provided, the recipient of the service would have suffered a considerable real loss; (c) the recipient has not provided evidence to suggest that she would have declined the service if she had had the opportunity to do so; and 
(d) the service provided was of adequate quality. If these conditions obtain and someone provides an unconsented service to another, the provider of the service is entitled to recover from the person she assisted, whether or not her service was successful. (This suggests that if the service is of poor quality but nonetheless succeeds, the service provider is not entitled to remedy. But the likelihood of dispute in such cases is low.)

The four conditions highlight the quasi-contractual aspect of this sort of liability, both by limiting liability to those situations in which contracts were not made only because of high transaction costs, and by their focus on the ex ante perspective. As with all cases of comparing reality to a hypothetical case, this approach raises a question as to which hypothetical situation we envisage and how different we make it from what actually took place: do we imagine the recipient in perfect health making a contract with the person who provided him with the service, or do we change the facts as little as possible from how things actually were and imagine the recipient consenting to a contract with the service provider in the last moments before losing consciousness? The latter situation may seem the better one because it is 'closer' to how things were. However, this case is problematic from a contractual perspective: it is hard to know what a market price for such a case would be, partly because there are not enough such cases to establish a market price. Further, in such cases it would be rational for the recipient to agree to pay anything for a treatment, down to the level of subsistence below which he would rather not stay alive, and because at this moment the particular service provider is a monopolist, it is possible that she will 
demand such a price.This implies that in such cases the recipient's willingness to pay would be strongly affected by his ability to pay, which differs considerably among people. More broadly, the latter scenario is one in which one's autonomy is compromised.As quasi-contractliability is supposed to be grounded in the same notions of autonomy that ground contractual liability, which were discussed in the beginning of this essay, clearly the first hypothetical is the one that fits it better. It is also the hypothetical that matches the liability rule proposed.

Another aspect of the proposal worth highlighting is that it does not try to identify emergency cases directly. Rather, it assumes that emergency cases are cases of 'considerable loss' (and not merely cases of foregone opportunity to make a profit) and limits recovery to them. The basis for this definition is psychological: even though from an economic perspective a lost profit is (more or less) similar to an actualloss of similar size, people tend to react very differently to actual losses and foregone benefits. ${ }^{50}$ The second and third conditions provide additional indirect guarantee that only true cases of emergency are captured in the definition. The claimant in such a case would have to show that transaction costs were high, or else her quasi-contractual claim would fail for not taking the contractual route when it was readily available.The third condition not only provides an easy way for the service recipient to avoid liability, but also helps identify rescue cases on the assumption that in other cases the recipient would have rejected the service. ${ }^{51}$

Another advantage of the suggested solution over that of free acceptance is 
that in cases that do not fall under it, the recipient will not have to reject the service because the provider will not be able to establish the first condition. Birks's solution requires the recipient of the service to actively reject the service or otherwise risk having to pay for it. Because the proposed alternative is more finely tailored to identify those instances in which liability should be imposed, in all non-emergency situations the recipient of a service will not have to do anything to avoid liability for unconsented services.

\section{FAIRNESS, QUASI-CONTRACT, AND UNJUST ENRICHMENT}

The discussion so far has sought to establish that many debates thought to belong to restitution are in fact more easily understood as debates about the boundaries of consent-based liability, and that even the most ardent defenders of restitution, under the veneer of the jargon of restitution or unjust enrichment, engage in the debate on those terms. The surprising finding there was that if we are interested in clear and open discussion, it is the language of restitution that is obfuscating and the language of quasi-contract that better highlights the relevant normative and doctrinal questions at hand. Those who care for the law speaking clearly would do well to return to speaking of quasi-contract. We have also seen that quasi-contractual analysis provides us with guidance when dealing with these cases, guidance that the vague and highly malleable language preferred by restitution lawyers does not. In particular we have seen that quasi-contractual analysis helps us understand why the typical remedy in rescue cases is 
quantum meruit. This remedy is unproblematic if we adopt the ex ante perspective suggested by quasi-contract, but it is odd if understood as part of a remedy for ex post gain-based restitution: potentially too low if the service proved successful, clearly too high if the service failed.

It would be a mistake, however, to think of the suggested quasi-contractual analysis as a panacea. No-one should expect a verbal formula or a 'test' to solve a normative problem. And no doubt the analysis proposed here raises difficulties that other analyses may avoid. We have already seen that the need to resort to counterfactuals about what the parties would have done always involves making some factual and normative assumptions. This, however, is inevitable: law is in the business of telling people what to do, so there is no avoiding engagement in normative inquiry.Two approaches, not always easily distinguishable, have tried to show why this last point is wrong. One approach sought to find the answer in the cases.This approach is appealing to its proponents, for it seemed to organise and harness what beforehand looked an unruly and disparate body of case-law into a neat and highly structured framework; at the same time it enabled its proponents to think that in engaging in this kind of inquiry they were doing 'pure' legal analysis, unadulterated by alien ideas coming from moral philosophy, economics or other disciplines.

The leading proponent of this approach was Peter Birks who defended it against 'realism', ${ }^{52}$ and who once wrote that in trying to explain restitution one should favour an approach that is 'downward-looking to the cases'. ${ }^{53}$ There is a growing sense that this approach has failed, and in retrospect it is not difficult to 
see why. Cases do not organise themselves into categories, and the categories themselves do not descend from heaven. They are based on certain normative assumptions that are there even if they are not explicitly mentioned. Very few now accept the view that there is a single principle of unjust enrichment that can explain all cases classified as restitutionary, and Birks's constantly changing views on questions of taxonomy may be the best evidence of the limitations of this approach. Arguably, many of those problems would have been avoided if he and others following him had been willing tolift their gaze up from the cases.

The alternative approach sought guidance in a normative principle, but one that was supposedly found in the cases.That principle, corrective justice, owes its appeal to the same attitude that motivated Birks's purely legal scholarship. It seemed thin, pale and simple compared to the more normatively ambitious attempts to explain private law as part of a distributive justice scheme, and it seemed to match the cases better than the often counterintuitive arguments offered by legal economists. It was hailed by its champions as a principle that is 'immanent' in the law, which in turn explains why there has been so much affinity between this view and doctrinal scholarship: if all the answers to what the law should be are already in the law, doctrinal scholars can go on doing what they have always been doing, helping the common law work itself pure without worrying much about the 'high theory' of the philosophers and the economists. Unfortunately, this closeness to the cases is exactly why corrective justice provides so little help in justifying the law. If understood as a conceptual claim about what unjust enrichment was about, it cannot explain what content this 
area of law should have, or for that matter why it should exist at all. If considered alternatively as a normative principle, it is open to the challenge that it conflicts with (and otherwise affects) other desired goals. Once this point is acknowledged, those who adopt the corrective justice view have to explain why a priori those other normative goals should be ignored in the context of private law litigation. ${ }^{54}$ What often happened was that in order to answer this question, proponents of the corrective justice view appealed to considerations such as separation of powers or the institutional capacity of courts. Whatever merit such arguments may have, they clearly are not internal to private law or corrective justice.

As I see it, a normative theory of a particular area of law must be made to fit two different questions. At the first level it must be explained within a broader account of the legitimate power of the state. In this respect 'private'law is no less in need of justification than criminal law or tax law. At the second level, however, every area of law raises unique normative questions that relate to the issues it governs. When discussing the foundations of liability in various areas of law there is a tendency to focus only on the second question and to assume that the answer to the question of legitimacy at the first level leaves the second level largely unaffected. Though this is a popular approach among private law theorists, it seems to me to be mistaken, or at least in need of justification, because it seems to load the dice in favour of certain normative views about private law. If I am right about this, it implies, for example, that what might be the best account of the conditions under which we are morally obliged to compensate people for 
harm we caused them may not be a good normative account of the area of law that governs these sorts of situations. It is, put simply, not obviously true that within the domain of private relations between individuals it is the job of the state to enforce only obligations that exist between individuals in the state of nature (whatever those obligations might be).

Plainly, this is not the place for addressing the question in what sort of ways questions on the first normative level may affect questions on the second. But when trying to address this question it will be useful to understand the sort of normative considerations that seem to be at play at the second level. In this sort of inquiry getting a firmer grasp on the pre-theoretical, moral intuitions at play is likely to prove useful, and since these matters have been subject to important empirical work in recent years it would be helpful to consider them here. ${ }^{55}$ Work in this area has identified what are believed to be the five basic components of interpersonal morality: harm, fairness, in-group loyalty, hierarchy, and purity. ${ }^{56}$ The most relevant in the present context are norms of fairness. In the course of a discussion that has little to do with unjust enrichment Daniel Kahneman and his colleagues suggested that ' $[t$ ]he cardinal rule of fair behavior is surely that one person should not achieve gain by simply imposing an equivalent loss on another' ${ }^{57}$ Though this description seems to capture the 'core case' of mistaken payment, ${ }^{58}$ it also captures (at least in general outline) other areas of the law that are not traditionally considered part of unjust enrichment (like the tort of conversion) and property (claims of vindication) as well as at least some aspects of breach of contract. As such, it does not help us identify unjust enrichment as 
a distinct area of law.

However, the psychological literature on fairness is useful in going beyond such fact situations to cases deemed unfair when one person takes advantage of circumstances in ways that do not impose real loss on another. Experimental studies on the ultimatum game are the classic example: in these experiments one of two players is given a sum of money (known to both).The first player is then requested to offer as much as she wishes from that sum to the other player.The second player, in turn, can either accept the offer, in which case she takes what she was offered and the first takes the remainder, or reject the offer, in which case both players get nothing. Experimental studies found that considerations of fairness often constrain both the initial offer and the decision whether to accept or reject it. Offers were typically equal or close to equal, and in cases where they were not, the recipient many times elected to reject the offer and thus forego a benefit (an 'incontrovertible benefit' in the language of restitution lawyers) in order to 'punish'behaviour deemed unfair. ${ }^{59}$

I believe it is these sentiments, and not a theory of corrective justice, that lie behind many of the doctrines nowadays usually classified as part of the law of restitution. To put it differently (and reinforce a point made above), whatever appeal the principle of corrective justice may have, it is one that derives from the fact that it seems to restore fairness in some cases of (perceived) unfairness.To give just one example, cases such as Pettkus v Becker, ${ }^{60}$ which involve the sharing of property between unmarried domestic partners upon the dissolution of their partnership, need not be explained on the basis of a broad-ranging concern to 
fight the unequal treatment of women in society. A narrower basis for such a decision (one that would be equally at play in the context of business partners) is the unfairness in any situation in which two people invest a comparable amount of work in an enterprise but only one of them gets the benefits. (In saying this I do not deny the significance of the legal recognition of the fact that domestic partnership is a domain to which norms of fairness apply and that certain social norms, perhaps norms relating to hierarchy, contributed to the unfair treatment of women.)

Fairness is, however, unpopular in some circles, so much so that many wish to eliminate it altogether from legal and political discourse. ${ }^{61}$ It is blamed for being both vague and undesirable for leading to unwanted outcomes. Our first task, therefore, is to provide a definition of fairness that is sufficiently precise and relevant to the current discussion. I propose the following definition, limited as it is to the context under consideration: a fair award for a good or service is one that corresponds, in the sense that it is neither considerably higher nor considerably lower, to other awards for similar goods or services.

There are various ambiguities (eg, is a snow shovel in the middle of the summer similar to a snow shovela day after a snow storm?) and limitations to this definition (are fairness norms inapplicable when there is no basis for comparison?). At the level of moral intuition, which is my focus here, I doubt there is much I can say about them. What interests me is to show why liability is more likely to be imposed in the cases I classified as quasi-contract than in some other cases that may also involve questions of fairness. What makes quasi- 
contract cases unique is that typically they call for the imposition of liability in situations that imitate efficient transactions, and as such they will be easier cases to accept even for those who are not friends of fairness in general.

This point requires a bit more elaboration: typical contracts are both efficient and fair. They are efficient because normally (ie, barring negative externalities and assuming moderate rationality and knowledge of the contracting parties) they will be entered where both parties stand to benefit from them. They are also fair because they are typically entered into in a market setting that (once again assuming moderate rationality of the contracting parties) will guarantee the fairness of the transaction. The emergency cases I propose to analyse as instances of liability for quasi-contract are those which are close enough to contractual cases so that we have sufficient reason to think that the imposition of liability in these cases will conform to both norms of fairness and the goal of efficiency.

This point helps us see the motivation behind many of the cases at the margin of contract that were discussed in the first section, and why liability is more likely to be imposed in the emergency cases discussed above than in some other cases that look superficially quite similar to them. Take, for example, cases of mistaken services and mistaken improvements. These typically take one of two forms: (a) A contracts with $B$ to provide her with a service; $B$ mistakenly provides the service to $C$; (b) $D$ improves what she mistakenly thinks is her property but which in fact belongs to E.These cases are similar to unconsented services cases, but are more complicated than them in that in neither of these imaginary scenarios has there been an attempt to circumvent the market. In addition, these cases are similar to 
cases of mistaken payment in that they (may) involve two innocent parties; they are, however, more complicated than mistaken payment cases, because in such scenarios typically the service provided cannot be undone.

Clearly the quasi-contractual analysis proposed above cannot be the basis for imposing liability in such cases. Can there be a different basis for the imposition of liability in these cases? This, if you want, is where we could define the domain of unjust enrichment beyond that of quasi-contract (rather than quasi-contract being part of unjust enrichment).Any defender of the idea of unjust enrichment as a separate basis for liability must answer this question affirmatively, for it is cases such as this in which fairness is exclusive justification for the imposition of legal liability. There are legal decisions imposing liability in such situations,${ }^{62}$ they are more controversial than cases of emergency. My suspicion is that, just as in the case of quasi-contract, successful claims will usually involve more than just fairness. Examples of that extra ingredient could be positive evidence of lack of negligence on part of the claimant and evidence that her actions in no way are an attempt to circumvent the market; some sort of fault on the part of the defendant (eg, in marking the boundaries of her property); the existence of some kind of proprietary interest and so on. If that is the case, that would suggest, consistent with the views of some unjust enrichment sceptics, that rather than an independent area of law explained by a unifying principle of unjust enrichment, the cases treated as belonging to the area of unjust enrichment are better understood as demonstrating the role of fairness as an auxiliary consideration that influences doctrines in tort, contract, and property law, rather than providing an 
independent basis for legal liability.

These are obviously tentative remarks on a broad topic. All they are meant to show is how the notion of quasi-contract helps us not only understand what falls underneath it, but also what falls outside of it, and how might such cases be treated.

\section{CONCLUSION}

Let me summarise what thinking about the margins of consent-based liability has taught us about certain cases usually treated as examples of liability for unjust enrichment. First, we have seen why the general rule was that there was no liability for unconsented services. We have seen that while in the case of mistaken payments or the mistaken provision of material objects in kind there is no danger that requiring the recipient to give up her benefit will somehow undermine the contractual foundations of the market system. I have then argued that what is at stake in the debate on free acceptance is the scope of consent-based liability, which, of course, is also the foundation of contractual liability. Based on these considerations I have argued that if we elect to impose liability in such circumstances there are good reasons for calling it quasi-contractual. This is not merely a helpful reminder to the general normative area in which this kind of liability belongs, but also a source of inspiration and borrowing: contract doctrine and contract theory are more elaborately developed and detailed than restitutionary doctrine and theory, and there are good reasons for 
examining them when considering the related area of free acceptance. Then, I have sought to explain how quasi-contractual liability helps us understand why in cases of emergency the law departs from its general policy of denial of liability for unconsented services, because, as in the case of mistaken payments, such cases do not typically increase the likelihood that people will abandon contracting as the usual method for acquiring goods and services. More importantly, I have argued that quasicontractual liability helps us understand two otherwise puzzling aspects of the law: first, why certain emergency cases did not limit liability to successful services; and second, why the level of compensation is measured at the market value of the service provided and not related to the value of the benefit gained by the service. In all this, the term 'quasi-contract', despite its quaint sound, is helpful in conveying something that the new terminology of restitution and unjust enrichment does not.

In the end I also suggested more tentatively that this discussion may be helpful for another question, namely the identification of the space that liability for unjust enrichment could occupy. Unjust enrichment is unique among other areas of private law in that both scholars and courts have expressed doubts about whether it 'exists' or whether all the doctrines classified under it are better understood as belonging to other areas of law. Debates over legal taxonomy are often pointless, especially when the categorisation is attempted on the basis of internal legal analysis. The analysis offered here, however, can be useful exactly because it does not attempt to identify 'correct' legal categories by examining legal materials. Looking beyond the law reveals in what sense such cases are 
different from normal contractual cases and in what sense there might be room for a distinct legal category of unjust enrichment. That discussion also made it clear in what sense such a liability would go beyond - and therefore would be more difficult to justify than - quasi-contractual liability. Whether this liability could ever be justified is a matter for another occasion. 


\section{Notes}

1 P. Birks, Unjust Enrichment (Oxford: Oxford University Press, 2nd ed, 2005) 271 (Birks, Unjust Enrichment). See also ibid, 57 where Birks talks about the 'artificialities' of the previously common analysis of unrequested services using contractual terminology. In an earlier book Birks wrote similarly that ' $[t]$ he trouble with language of this kind [ie of 'quasi-contract'] is twofold. It displaces the truth. And it introduces a lie.'P. Birks, An Introduction to the Law of Restitution (Oxford: Clarendon Press, paperback ed, 1989) 22 (Birks, Introduction).

2 A. Burrows, The Law of Restitution (Oxford: Oxford University Press, 3rd ed, 2011) 28. For similar criticisms of the term see M. McInnes, The Canadian Principle of Unjust Enrichment:Comparative Insights into the Law of Restitution' (1999) 37 Alta L Rev 1, 4 (the term is 'misleading' and based on 'pure legal fiction'); G. Virgo, The Principles of the Law of Restitution (Oxford: Clarendon Press, 2nd ed, 2006) 21 ('reliance on quasi-contractual reasoning should have no part to play in the modern law of restitution'), 44 (the law used to be 'founded on the fiction of implied contract... [and] it is essential that such fictions do not reappear').

3 Birks, Unjust Enrichment n 1 above, 275. Birks also says that '[f]or the most part [the word 'unjust'] merely gathers up the law's reasons, not being contracts or wrongs, why an enrichment should be given up to a person at whose expense it was received'ibid, 274. If anything, Burrows is even stronger. He says that the law of unjust enrichment is 'what the law regards as unjust enrichment' and not what 'any one individual or commentator may think is unjust enrichment'. Burrows, $\mathrm{n} 2$ above 4 ; also ibid 26,86 . See also the text accompanying $n 42$ below.

4 See the words quoted in the previous note.

5 See eg W.A. Keener, A Treatise on the Law of Quasi-Contracts (New York: Baker,Voorhis, 1893) 16. 6 Rhodes v Rhodes (1890) LR 44 Ch D 94, 107 (CA). Similarly: Sinclair v Brougham [1914] 1 AC 398, 416 (HL) ('the law is ready to imply a debt in such cases arising quasi ex contractu'); City of Chattanooga, Tennessee v Louisville \& Nashville Railroad Co 298 F Supp 1, 9 (EDTenn 1969) ('the law implies a promise to make restitution to the extent of the unjust enrichment').

7 Baylisv Bishop ofLondon [1913] 1 Ch 127,140. For a contemporaryversion of exactly this fear see M. McInnes, "ResistingTemptations to "Justice"'in R. Chambers et al (eds), Philosophical Foundations of the Law of Unjust Enrichment (Oxford: Oxford University Press, 2009) 100.

$8 \mathrm{I}$ am not the first to argue that some of what is currently treated as belonging to unjust enrichment could be helpfully modeled on something like contract. See S. Hedley, 'Implied Contract and Restitution' (2004) 63 CLJ 435; P. Jaffey, The Nature and Scope of Restitution (Oxford: Hart Publishing, 2000) chs 3-4, and from an economic perspective R. A. Long, 'A Theory of Hypothetical Contract'(1984) 94 Yale LJ 415.The argument, however, is developed rather differently.

9 See J. Beatson, The Use and Abuse of Unjust Enrichment: Essays on the Law of Restitution (Oxford: Clarendon Press, 1991)31-32.

10 See J.A. Henderson, 'Process Constraints in Tort' (1982) 67 Cornell L Rev 901.

11 On the relationship between contract and autonomy see generally L. L. Fuller, 'Consideration and Form' (1941) 41 Colum L Rev 799, 806-810; C. Fried, Contract as Promise (Cambridge: Harvard University Press, 1981) 14-17. Many doctrines of contract law reflect the other side of the coin, namely that we are likely to set aside a contract when we suspect that for some reason it does not reflect the autonomous choice of the parties.

12 R. Goff and G. Jones, The Law of Restitution (London: Sweet \& Maxwell, 1966) 30-31.The ellipses skip references to the receipt of goods, but as explained in the text goods can be handled differently because they can be returned in kind. See McDonald v Coys of Kensington [2004] EWCA Civ 47, [2004] 1 WLR 2775. In this respect they are closer to money than to services.This was recognised in more recent editions of Goff and Jones. See Lord Goff of Chieveley and G. Jones, The Law of Restitution (London: Sweet \& Maxwell, 7th ed, 2007) §1-027.

13 Birks, Introduction $\mathrm{n} 1$ above, 265. In a later essay Birks clarified this example by adding a test: the householder is liable in this situation if he "ha[d] reason to believe that, if the [cleaner] knew what was in [the householder's] power to tell him, the [cleaner] would desist'. P. Birks, 'In Defence of Free Acceptance'in A. Burrows (ed), Essays on the Law of Restitution (Oxford:Clarendon Press, 1991) 105, 121.The similarity between this test and tests for contractual reliance is clear.

14 See ibid, where Birks somewhat qualified the view he expressed in Birks, Introduction $\mathrm{n} 1$ above; see also Birks, Unjust Enrichment n 1 above, 56-58.

15 See A. Burrows,'Free Acceptance and the Law of Restitution' (1988) 104 LQR 576; G. Mead,'Free Acceptance: Some Further Considerations' (1989) 105 LQR 460; A. Simester, 'Unjust Free Acceptance'[1996] LMCLQ 103; M. Garner, 'The Role of Subjective Benefit in the Law of Unjust 
Enrichment' (1990) 10 OJLS 42; see also S. N. Ball, 'Work Carried Out in Pursuance of Letters of Intent-Contract or Restitution'(1983) 99 LQR 572, 576-578.

16 Burrows, ibid, 578. This is a direct response to Birks, Introduction n 1 above, 276. Notice by the way, that contrary to Burrows's words quoted in $n 3$ above, considerations of justice do, inevitably, enter his argument.

17 The optimal contract then is not one that allocates all risks, but one that has the overall highest expected value. Some risks are so unlikely to materialise that it is undesirable to hedge them. See S. Shavell, Foundations of Economic Analysis of Law (Cambridge: Harvard University Press, 2004) 299-301.

18 See A. T. von Mehren, 'Contracts in General' in International Encyclopedia of Comparative Law (Tübingen: Mohr, 1992) vol vii, §9-19-\$9-22 for a discussion of German cases that relied on a broad contractual analysis. These cases would undoubtedly have been analysed as restitutionary by Burrows

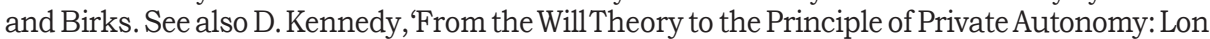
Fuller's "Consideration and Form"' (2000) 100 Colum L Rev 94, 143 ('The civilians made it easy to create binding contractual obligations in situations in which the common law consideration doctrine made it hard').

19 Birks, Introduction $\mathrm{n} 1$ above, 275.

20 Furthermore, Birks allows for the free acceptance claim even when there was a completely performed contract between the parties, ibid, 287.

21 ibid, 276 (emphases added). And also:The person who knows a benefit is being conferred on him and secretly lies by ... is not satisfactorily distinguishable from one who accepts offered goods by taking them in.' ibid, 465-466.

22 ibid, 282.

23 Birks, $\mathrm{n} 13$ above, 119. Birks claims, ibid, 127, that a contractual explanation of this situation is wrong, but without the (quasi-) contractual explanation offered in the text it remains entirely obscure why the recipient's behaviour is unconscientious.

24 See British Steel Corporation v Cleveland Bridge and Engineering Co Ltd [1984] 1 All ER 504 (QB).

25 E. McKendrick, 'The Battle of the Forms and the Law of Restitution'(1988) 8 OJLS 197, 212 (emphasis added).

26 See Mead, n 15 above, 463. I believe this was also Burrows's point in the quote accompanying n 16. Another argument offered by Mead is that there will be practical difficulties in drawing the boundaries of free acceptance. ibid, 464-466. Mead stresses the importance of 'formalities' in entering into a contractual relationship, making it clear yet again that what he cares about are the boundaries of consent-based liability. ibid, 466.

27 See ibid, 461-462; Simester, n 15 above, 116-120, especially at 118. Simester also considers the possibility of grounding free acceptance liability on the service provider's mistake in believing the recipient is going to pay her. ibid, $110-116$. His rejection of this possibility is again revealing: The prospect of a reciprocal transfer is precisely the subject of the [service provider's] risk-taking. . . [and] it is ... his very motive for initiating the transaction'. ibid, 114 .

28 Burrows, $\mathrm{n} 15$ above, 598; see also Garner, $\mathrm{n} 15$ above, 65.

29 In fact, a true restitutionary remedy should in most cases be at least equivalent to quantum meruit and often higher. Normally a person would not pay X for a service unless she believed her subjective benefit from it was more than X. In such cases, a remedy that aimed to strip the recipient of a service of the gain she made would entitle the service provider, at least in principle, to offer evidence that the defendant's gain was higher than the market price for the service.

30 Burrows on the other hand is willing to entertain this possibility in a manner that, again, reveals the artificial analysis forced upon us by restitution: he claims that when a contract for a service at more than market price does not materialise but a service is provided, it is the contract price that should be the basis for the restitutionary claim. Burrows, $n 2$ above 60 . Again, it is simpler to change the rules of entry into contract instead of treating such cases as restitutionary.

31 See Birks, $n 13$ above, 118-119.

32 ibid, 119, 120; see also Simester, n 15 above, 122-127.

33 A.W. B. Simpson,'Historical Introduction' in Cheshire, Fifoot \& Furmston's Law of Contract (Oxford: Oxford University Press, 15th ed, 2007) 1, 13. For a discussion on how even the shifts that did occur in contract law occurred from within existing legal categories see D. Ibbetson, A Historical Introduction to the Law of Obligations (Oxford: Oxford University Press, 1999) 246-248.

34 A similar phenomenon, although for somewhat different reasons, has been identified in the borderline between contract and tort, where the rigidity of the rules about the entrance into contract has led to cases which are 'equivalent to contract' (Nocton v Lord Ashburton [1914] AC 932, 972 (HL); approvingly elaborated by Lord Devlin in Hedley Byrne \& Co Ltd v Heller \& Partners Ltd [1964] AC 465, 525-30 (HL)), being analysed in tort. For a critique of English law on this point see 
B. S. Markesinis, 'An Expanding Tort Law:The Price of a Rigid Contract Law'(1987) 103 LQR 354, 384-97.

35 For a survey of US doctrine that highlights the shifting grounds between contract and restitution in twentieth century law see S. D. Henderson, 'Promises Grounded in the Past:The Idea of Unjust Enrichment and the Law of Contract' (1971) 57 VaL Rev 1115, 1143-1154, 1176-1183. In earlier times similar trends could be identified in English law as well. See Ibbetson, $\mathrm{n} 33$ above, 269-272.

36 See generally P. S. Atiyah and R. S. Summers, Form and Substance in Anglo-American Law: A Comparative Study of Legal Reasoning, Legal Theory, and Legal Institutions (Oxford: Clarendon Press, 1987) 70-95, 115-133.

37 For some comparative comments on the status of consideration in English and American law see Atiyah and Summers ibid, 84-85; Markesinis, n 34 above, 371-373. For a more detailed description of the doctrinal changes in American contract law see M. B. Metzger and M. J. Phillips, 'Promissory Estoppel and the Evolution of Contract Law'(1980) 18 Am Bus LJ 139.

38 A similar analysis is applicable to cases of limitations on contracting power due to age, capacity, failure to comply with a required formality and similar conditions. See Hedley, $\mathrm{n}$ above, 440-447.

39 See generally J. D. McCamus, 'Necessitous Intervention: The Altruistic Intermeddler and the Law of Restitution'(1979) 11 Ottawa L Rev 297.

40 Burrows, $n 2$ above 480; see also McCamus, ibid, 311. Later Burrows also suggests without much conviction that '[p]erhaps loosely it could be said that [the plaintiffs] had lost the opportunity to bargain with the defendant for their time and labour'. Burrows, ibid 485. But this is unconvincing as no-one asked the plaintiffs to intervene in such circumstances in the first place.

41 This is particularly problematic coming from Burrows, one of the few to still hold to the view that restitution has structural and normative unity. See A. Burrows, 'Quadrating Restitution and Unjust Enrichment:A Matter of Principle?' [2000] Restitution L Rev 257. A similar problem has bedevilled Birks's 'policy-motivated restitution', which he discussed in Birks, Introduction n 1 above, 294-311. First, as Birks admits, all restitution is in a sense 'policy-motivated', ibid, 294. (One could add that in a sense all liability is policy-motivated.) Second, in the end this category simply lumps all the cases in which there are 'reasons for restitution which override the policy which dictates that, in general, a volunteer who cannot establish a free acceptance should not have restitution'. ibid.This provides no guidance as to what those cases might be.As discussed in the text, later in life Birks came to the conclusion that such cases cannot be fit within his restitutionary framework at all.

42104 SW 164 (Ark 1907). Matheson v Smiley [1932] 2 DLR 787 (Manitoba CA) (Matheson) is a similar Canadian case, which involved a failed attempt to rescue a person who shot himself. (Most commentators assume this was a suicide, but even though this is the likely explanation, the reported facts are consistent with accidental shooting; the potential significance of this point is discussed in $\mathrm{n} 51$ below. Matheson was disposed of in the same manner, using the notion of liability 'quasi ex contractu'.ibid, 790; and cf Lambv Bunce (1815) 105 ER 836,4 M \& S 275, which did not involve a failed treatment, but explicitly stated that when there is no contract in a case of emergency, "the law will raise a promise on ... part [of those who stand by and do not object] to pay for the performance'. ibid, 277.

43 Burrows, $n 2$ above 484. Birks, by contrast, was aware of these problems as is evident from his brief remarks in Birks, Unjust Enrichment n 1 above 23, 288.

44 Burrows, for instance, states that in most cases of emergency (except salvage) the remedy is 'reimbursement and remuneration.'Burrows, ibid 486. His analysis thus confuses ex post basis for liability with ex ante remedy (in the case of success) and ex post remedy (in the case of failure).

45 Could we explain why salvage cases and Cotnam-type cases are governed by different rules? In a perfectly competitive market with perfect information a rescuer's expected gain in both situations would be the same. But perhaps the difference has to do with the fact that historically there was no market for salvage at sea and so it was difficult to assess the value of the service for attempted salvage, thus undermining the possibility of using quasi-contractual analysis.There may also be evidentiary problems that explain the different rule regarding salvage. Assuming the costs of rescuing are equal under both regimes, potential rescuers would rescue under the one regime when the expected gain is higher than the cost of rescue. In a quasi-contractual regime the probability of gain would be 1 but the gain would be relatively low. In the existing salvage regime the probability of gain is lower but the expected gain is probably higher.

46 See F.D. Rose, Kennedy \& Rose:The Law of Salvage (London: Sweet \& Maxwell, 7th ed, 2010) $\S \S 9.001-9.002$; Burrows, $n 2$ above 475. For the claim that the law of salvage should be understood as part of the law of restitution see Rose, ibid §1.035. Birks was attentive to the difficulties with this analysis, and in particular to the fact that the remedy in such cases is not typically restitutionary. Birks, Introduction $\mathrm{n} 1$ above 307. Nonetheless he initially included such cases within 'category three' restitutionary cases. ibid. This was still his view in P. Birks and C. Mitchell, 'Unjust Enrichment'in 
P. Birks (ed), English Private Law (Oxford: Oxford University Press, 2000) vol ii, §§15.156-60. However, he later changed his mind, and consigned such cases to the miscellaneous fourth category. Birks, Unjust Enrichment 1 above 22.

47 This sends devastating ripple effects on his third category of unjust enrichment. See C. Webb, What is Unjust Enrichment?'(2009) 29 OJLS 215.

48 Burrows, $\mathrm{n} 2$ above 484. Whether or not we decide to impose liability on unsuccessful services has little to do with any of the questions that are traditionally asked by restitution lawyers when deciding whether liability should be imposed or not. For this reason, while Burrows still asserts that salvage requires success, Burrows, ibid 484, he offers no explanation why. (Quasi-)contractual analysis, by contrast, fares better. Seen 45 above.

49 Incidentally, for evidentiary reasons we may still wish to opt for the rule according to which the provider is entitled to compensation only in the case of success, because of concern that it will be too difficult in circumstances of emergency treatment to identify those cases in which the provider performed well but nonetheless failed and those cases in which her performance was sub-par. We may then use the measure of success as raising a presumption (perhaps even an irrebuttable one) that when the service failed the performance was inadequate.

50 See D. Kahneman etal, 'The Endowment Effect, Loss Aversion, and Status Quo Bias'(1991) 5 J Econ Perspectives 193; D. Kahneman and A. Tversky, 'Loss Aversion in Riskless Choice: A Reference-Dependent Model'(1991) 106 QJ Econ 1039.

51 A case like Matheson, mentioned in $\mathrm{n} 42$ above, raises a difficulty in this context: a person committing suicide is arguably someone whose actions display no desire to be helped. Would a rescuer in such a case not be entitled to remuneration? There are possible arguments either way, not all of them limited to consent. As we have seen, Burrows comes close to quasi-contractual analysis, but forces it into restitutionary categories. In this context he argues that lack of consent could be seen as evidence for no benefit. Burrows, $n 2$ above 484. It seems more natural to say that lack of consent is evidence of lack of consent.

52 See P.Birks, 'Equity in Modern Law:An Exercise in Taxonomy'(1996) 26 UW Australia L Rev 1, 97-99; for a similar attitude see R. Stevens, Torts' in L. Blom-Cooper et al (eds), The Judicial House of Lords 1876-2009 (Oxford: Oxford University Press, 2009) 629, 651-52.

53 Birks, Introduction $\mathrm{n} 1$ above 22. Birks even says that to the extent the principle distances us from the cases 'it is to be regarded with suspicion.'ibid 23. See also the words of Burrows quoted in $n 3$ above.

54 This dilemma is fatal to the views expressed in McInnes, $\mathrm{n} 7$ above.

55 Birks is strongly opposed to giving any role to intuition, which he contrasts with 'rationality'. See P. Birks, 'Equity, Conscience, and Unjust Enrichment'(1999) 23 Melbourne U L Rev 1,20-22.

Birks, however, does not avoid his moral intuitions by not discussing them. They are either hidden in his argument, or he relies vicariously on the intuitions of thejudges on whose judgments he bases his account of the law.In any case, as I stress in the text, the content and ultimate justification of any area oflawis not simply thelegislation of moralintuitions, butrather requires a morecomprehensive account of the legitimacy of state power.

56 See J. Haidt, 'The New Synthesis is Moral Psychology' (2007) 316 Science 998.

57 D. Kahneman et al,'Fairness as a Constraint on Profit Seeking: Entitlements in the Market'(1986) 76 Am Econ Rev 728,731.

58 Birks, Unjust Enrichment $\mathrm{n} 1$ above ch 1.

59 See W. Güth et al, 'An Experimental Analysis of Ultimatum Bargaining'(1982) 3 J Econ Behav \& Org 367; D. Kahneman etal, 'Fairness and the Assumptions of Economics'(1986) 59 J Bus S285.

60 [1980] 2 SCR 834.

61 See L. Kaplow and S. Shavell, Fairness Versus Welfare (Cambridge: Harvard University Press, 2002) 69-81, passim; R. A. Epstein, 'Unconscionability: A Critical Reappraisal' (1975) 18 JL \& Econ 293 at 304; see also 'Against Fairness' Economist 1 July 2010 at http://www.economist.com/node/ 16485338 (last visited 5 October 2011).The earlier caveat in the text about the difference between an explanation of existing legal doctrines and their justification means that, within a broader justificatory account of law, fairness may have little or no place.

62 See eg Greenwood v Bennett, [1973] QB 195 (CA). In the United States, likewise, liability has sometimes (but not always) been imposed in such cases. See A. Kull,'Mistaken Improvement and the Restitution Calculus' in D. Johnston and R. Zimmermann (eds), Unjustified Enrichment: Key Issues in Comparative Perspective (Cambridge: Cambridge University Press, 2002) 369. Perhaps not surprisingly, nineteenth century law tended to be less sympathetic to such considerations: Falcke v Scottish Imperial Insurance Co (1886) 34 Ch D 234, 248-249 is clear that there is no scope for liability beyond that arising from contract. 
